\title{
Escuela y construcción de identidades de género: una aproximación a la masculinización de los varones en edad pre-escolar
}

\author{
School and Construction of Gender Identity. An \\ aproach to boys' masculinization at Pre-school
}

Marina E. Tomasini ${ }^{1}$

\section{Resumen}

Este artículo trata sobre la construcción de identidades de género en los varones en la educación pre-escolar. Se presenta un conjunto de análisis provenientes de una investigación realizada en tres centros de educación inicial en Córdoba, Argentina. Dentro de las interacciones que emergen en la cotidianeidad escolar hay una serie de actuaciones que son interpretadas como parte del proceso de masculinización y se caracterizan por: la centralidad que adquiere el cuerpo en las interacciones entre varones, mediante las agresiones físicas y en juegos corporales; el protagonismo de algunos niños en actos de hostigamiento hacia otros/as compañeros/as; la tendencia de algunos a implicarse en conflictos entre niñas e intentar resolverlos por medio de la violencia física. Se consideran algunas formas por las cuales las intervenciones docentes constituyen sentidos que refuerzan determinada identidad de los "varones" como clase problemática en relación a la disciplina y el orden escolar.

Palabras clave: Masculinidad, Violencia, Conflicto, Educación preescolar.

1 Doctora en Psicología. Docente e investigadora. Facultad de Psicología, Universidad Nacional de Córdoba. Ciudad de Córdoba, Argentina. Correo electrónico: marinatomasini@hotmail.com. 


\section{Abstract}

The present article focuses on the construction of gender identity in boys at kindergarten, recuperating observations and analyses of a research in three Pre scholars groups, in Córdoba, Argentina. As part of everyday interaction, there are some actions that are view as part of masculinity process and its characteristics are: the centrality of body in boy's interactions, by physical aggression or in corporal plays; bulling to other classmates; taking part in girl's conflicts and using physical violence to resolve some fights. At the same time, are consider some ways that teachers interventions reinforce the boys identity as problematic class respect the school discipline and order.

Key words: Masculinity, Violence, Conflict, Pre-school education.

\section{Introducción}

La introducción del concepto de género en el campo académico a partir de los sesenta tuvo el propósito de diferenciar una construcción social y cultural específica del sexo como condición biológica. Desde los años treinta la visión biologista había dominado el punto de vista de los comportamientos del hombre y la mujer (Conway, Bourque \& Scott, 1996). En las últimas décadas la aproximación al género ha ido cambiando, desde el aprendizaje de roles femeninos y masculinos mediante una socialización cultural unidireccional hacia una comprensión de la formación de identidades genéricas como proceso relacional, múltiple y diverso. Los conceptos de masculinidades y feminidades han empezado a pensarse más recientemente como construcciones continuas en un campo social de relaciones de poder. En esta línea, Judith Butler (2001) propone una visión del género como una creación continua a través de actuaciones (performance) y actos repetitivos que constituyen la ilusión de un género natural, debido y estable, de modo que el género no se origina súbitamente en algún punto del tiempo después del cual su forma quedaría fijada. 
En los ochenta se demarca más claramente un campo de estudios sobre masculinidad. El trabajo de Connell (1995) ha sido una referencia central en el tema. Según este autor, el ideal arquetípico de masculinidad en nuestras sociedades se vincula con la misoginia, la homofobia, la violencia, las conductas desafiantes y riesgosas. Si bien los modelos masculinos adoptados por la mayoría de los hombres no se corresponden con este ideal, el mismo actúa como un ordenador que resulta de gran eficacia simbólica. Así se entendería el padecimiento de los varones que se alejan abiertamente del modelo hegemónico y la presión que recae sobre los chicos para acercarse al modelo ideal de varón masculino (Alonso \& Morgade, 2008).

Olavarría (2003) reconstruye algunos de los temas investigados en el contexto latinoamericano. Los primeros trabajos tuvieron como objeto el machismo y el marianismo en la región, como dos expresiones de identidades y relaciones de género que interactuaban entre sí y que serían prevalentes desde la época de la conquista. A partir de la segunda mitad de los noventa se abrieron intereses en torno a las masculinidades. Algunas de las líneas investigativas han sido las identidades masculinas, la salud sexual y reproductiva, las paternidades y las experiencias de varones jóvenes y adolescentes. Se trata de un conjunto de trabajos orientados a conceptualizar cómo los hombres construyen su masculinidad y cómo la misma se asocia con la sexualidad, la reproducción, la paternidad, el trabajo y la violencia.

Aunque no se ha podido establecer la existencia de un modelo masculino universal, un dato recurrente en distintas sociedades es que los pilares que sostienen la identidad masculina del varón están ligados a la represión de lo "femenino" e "infantil", en tanto condiciones asociadas a la pasividad y dependencia (Gilmore, 1994; Burin \& Meler, 2000; Zattara \& Skoumal, 2008). De modo que una de las formas predominantes de constituirse en varón masculino pasan por la subordinación de posiciones subjetivas femeninas o masculinas alternativas (Renold, 2001).

Más específicamente, un conjunto de estudios ha analizado la particularidad del escenario escolar en los procesos de constitución y demostración de masculinidad. Los varones manifestarían un sí mismo masculinizado de diversas maneras: a través del desafío a las figuras de autoridad y la confrontación abierta con los docentes; por medio de la desestimación de 
los asuntos académicos, que puede generar situaciones de abuso verbal u hostigamiento hacia quienes son percibidos en una actitud "pro-escuela"; produciendo discursos y prácticas de lucha, y usando la violencia física legítima (en los deportes) e ilegítima (altercados y golpes), involucrándose en actuaciones violentas y agresivas (Younger, Warrington \& Williams, 1999).

Uno de los temas analizados es la feminización del mundo académico y sus derivaciones en las relaciones entre compañeros (Marsh, Parada, Seeshing \& Healy, 2001). Los chicos realizan variadas transacciones ante la tensión entre la percepción de la feminización de sus actuaciones escolares y la presión de la masculinidad hegemónica (Renold, 2001; Dumais, 2002). Así, jóvenes que en la intimidad pueden ser afectuosos con sus amigas y novias, ante la mirada de sus compañeros las tratan con indiferencia o agresivamente (Lomas, 2007).

Se señala, además, una contraposición entre la cultura masculina del patio y la cultura femenina del aula (Lomas, 2007). Trabajos etnográficos documentaron una apropiación diferencial de los espacios durante el recreo. Mientras que los varones tienden a expandirse, las chicas tienden a restringirse espacialmente (Acuña, 2004). Ellos suelen ocupar las zonas centrales del patio; ellas acostumbran ubicarse en lugares periféricos, donde llevan a cabo conversaciones y juegos más tranquilos (Wenetz, Stigger \& Meyer, 2006). En el tiempo de recreo cobran relevancia, entre los varones, actuaciones con tendencia a la "fisicidad", caracterizadas por un fuerte despliegue corporal. Un caso destacado lo constituyen los juegos corporales donde se mide fuerza (Blanco, García, Grissi \& Montes, 2006). Beer (2008) analizó que desde el discurso escolar se justifica este enmarcamiento espacial de las chicas en la supuesta necesidad de protección de sus cuerpos, dada la brusquedad de las actividades de sus compañeros. La rudeza en el trato de los varones es concebida como normal, ya que estaría basada en una diferencia biológica. De este modo se refuerzan ideas estereotípicas como la fragilidad, delicadeza y tranquilidad femeninas, y la fuerza, rudeza e impulsividad masculinas.

Ahora bien, es notable que los estudios sobre el tema se hayan concentrado en los cursos más altos de la escolaridad primaria y en la escuela secundaria, con lo cual no hay demasiada información sobre la masculiniza- 
ción en las relaciones entre compañeros/as en la escolaridad de nivel inicial. Por ello resulta clave documentar la relación entre las prácticas de masculinización y el ingreso al mundo escolar al menos por dos motivos fuertes:

a) la particular relevancia que adquiere la edad de los/as preescolares para el desarrollo subjetivo de género. Estudios psicológicos han evidenciado que entre los tres y los cuatros años los/as nińos/as empiezan a expresar crecientemente nociones sobre un conjunto de expectativas de comportamiento diferenciadas para cada sexo (Levy, Taylor \& Gelman, 1995; Crick, Bigbee \& Howes, 1996; Welch-Ross \& Schmidt, 1996; Bigler Jones \& Lobliner, 1997; Lloyd \& Duveen, 2003).

b) las implicancias socializadoras del ingreso al mundo escolar, que ubica a chicas y chicos en un nuevo entorno normativo y relacional. Particularmente se destaca la sociabilidad entre pares, ya que en la escuela los/as chicos/as son agrupados/as por edades. Hartup (1995) puntualiza que en los intercambios con los de la misma edad, aunque haya diferencias en cuanto a talla, habilidades sociales, destrezas físicas, es más factible que puedan negociar reglas, entrando en un conflicto como parte igual. Asimismo la interacción entre pares proporciona una oportunidad de experimentar la agresividad con los "iguales", lo cual lo torna un ámbito significativo para la socialización.

Aunque la relativa independencia que puedan tener los niños en sus intercambios no convierte a las relaciones entre pares en un ámbito exento de regulaciones institucionales, las prescripciones sobre el uso de espacios, tiempos, objetos y las normas de interacción entre compañeros, entre otras, forman parte de la normatividad que estructura la vida social en la escuela. Especialmente la regulación institucional se encarna de modo privilegiado en las intervenciones normativas de los agentes educativos. En lo que hace a la generización, tales intervenciones cobran distintos sentidos que pueden tanto reforzar procesos de segregación intersexual o de orientación infantil según estereotipos genéricos como favorecer el cuestionamiento de nociones de género naturalizadas o fomentar formas de relaciones no discriminatorias inter e intra género.

De lo dicho hasta el momento se presupone que: los/as chicos/as en edad pre-escolar disponen de recursos incorporados para comprender ciertos significantes como signos de género y, a su vez, para producir estos 
signos en sus interacciones con los demás. La incorporación al mundo de la escuela implica la interacción sistemática con los pares, con lo cual adquiriría relevancia la entronización en la clase genérica. Esto implica para los/as pequeños/as la exhibición de rasgos y atributos del propio género. La exigencia de actuar acorde a lo esperado para los de la misma categoría sexual sería más disruptiva con el orden normativo escolar en el caso de los varones, toda vez que son inducidos a constituir cursos de acción ligados con el uso de la fuerza y con actitudes desafiantes e intimidatorias.

Aunque las exigencias de masculinización, provenientes de un orden simbólico que exalta la virilidad, el riesgo y la violencia, pueden impactar diferencialmente entre varones de distintos grupos sociales y entre los chicos de un mismo sector social, por lo que es necesario explorar la variabilidad de posiciones y actuaciones entre los niños, el género se transversaliza con otros clivajes de diferenciación e identidad.

Estos supuestos han orientado un estudio sobre el proceso de generización en ámbitos de educación inicial, en la ciudad de Córdoba, Argentina ${ }^{2}$. En este artículo se presentan algunos de los resultados obtenidos con el propósito de:

a) Caracterizar las actuaciones de masculinización que acontecen en ámbitos educativos de nivel inicial y analizar su incidencia a nivel de las relaciones inter-género como intra-género, así como las variaciones entre los distintos grupos estudiados.

b) Establecer conexiones entre estas prácticas y las relaciones de los varones con la disciplina y el orden normativo escolar, con el propósito de aportar información sobre la incidencia del género en el inicio de las trayectorias escolares de los pequeños.

\section{Metodología}

La investigación fue conducida como un estudio de casos, porque se buscaba describir y caracterizar en detalle el entramado cotidiano de

2 Este trabajo es parte de la tesis de Doctorado en Psicología, titulada: "Intersubjetividad y Género. Procesos de interacción en la socialización temprana” (iniciada con beca de la Secretaría de Ciencia y Técnica de la Universidad Nacional de Córdoba y finalizada con beca del Consejo Nacional de Investigaciones Científicas y Técnicas de Argentina). 
los ámbitos educativos donde acontece la generización. Esto implicaba penetrar en cierta diversidad fenoménica para elaborar conceptualmente la interrelación entre distintas dimensiones y niveles de análisis. Se trata de la comprensión de procesos y significados contextuados para establecer líneas analíticas que aporten en la comprensión teórica del fenómeno en estudio (Stake, 1998; Flick, 2004).

En base a un muestreo intencional, se seleccionaron tres salas de niños/as de cuatro años, de centros educativos de la ciudad de Córdoba, Argentina. Con el fin de ampliar el rango de situaciones observadas y explorar uniformidades y variaciones de las mismas en diferentes contextos, se escogieron grupos de sectores socioeconómicamente contrastantes. Dos salas pertenecen a un jardín dependiente del estado provincial y atienden a niños/as que viven en sectores de pobreza de la ciudad. La otra se inserta en un establecimiento privado que atiende a nińos/as de un sector poblacional medio-alto.

Cuadro 1. Casos seleccionados y sujetos observados

\begin{tabular}{|c|c|c|}
\hline Casos & Sujetos & Sector \\
\hline 1 & $\begin{array}{c}12 \text { niñas, 9 niños (entre 42 y 54 meses) y 3 agentes } \\
\text { educativos. }\end{array}$ & Pobreza \\
\hline 2 & $\begin{array}{c}11 \text { niñas, } 7 \text { niños (entre 42 y 54 meses) y 3 agentes } \\
\text { educativos. }\end{array}$ & Pobreza \\
\hline 3 & 12 niñas, 9 niños (entre 42 y 54 meses) y 4 agentes \\
educativos.
\end{tabular}

La observadora se incluyó desde el inicio de clases en todos los espacios donde se llevaban a cabo las actividades y realizaba registros in situ. Se efectuaron observaciones de toda la jornada, tres veces por semana, durante los dos primeros meses, y luego se continuó con una frecuencia semanal a lo largo de todo el ciclo anual. Para este artículo se recupera una serie de análisis elaborados sobre información proveniente de las observaciones y entrevistas con los agentes educativos.

Tras una primera etapa, donde se realizaron observaciones poco focalizadas, se definió como unidad central de observación a los incidentes conflictivos. Se trata de episodios de disputa entre niños/as que pueden o no 
registrar una intervención reguladora de parte de algún agente educativo, o bien, de incidentes conflictivos entre nińos/as y los agentes educativos. Estos eventos son entendidos como micro-secuencias de tematización normativa, dado que, a raíz de una situación conflictiva que interfiere una actividad en curso, se actualizan normas o reglas que se convierten en el tema dominante de la situación interactiva.

El proceso de análisis se fue realizando en forma simultánea a la recolección de datos, proveyendo a esta última de informaciones que permitieron ajustar los criterios de observación, focalizar problemáticas y profundizar la pesquisa en función de las líneas interpretativas que iban definiéndose como relevantes en relación a los objetivos de la indagación. Para el desarrollo de las categorías predominó un procedimiento inductivo.

Para el análisis de episodios conflictivos se siguió una línea heurística propuesta por Colomina, Mayordomo y Onrubia (2001) y se tomó cada incidente como una secuencia de acción, lo cual supone identificar su inicio, desarrollo y finalización (aunque provisoria). Para profundizar el análisis desde esta lógica secuencial se encontró un antecedente en la investigación de Ynoub (2002), quien utilizó categorías del Derecho Procesal como recurso descriptor y guía heurística del material empírico. Esto permitió organizar el análisis de los incidentes en etapas: a) introductoria (motivos que abren el incidente y el objeto del mismo): 1. demanda (identificación del momento en que ella ocurre y las acciones que se siguen hasta que un agente educativo toma parte en el asunto); 2. defensa (acciones producidas por la parte demandada con el fin de contrarrestar, negar los hechos u ofrecer justificaciones); b) probatoria (actuaciones dirigidas a investigar: preguntar, recurrir a testigos, pedir nuevos testimonios a las partes, etc.); c) conclusional (resolución del incidente: obligaciones impuestas, sanciones, etc.).

El análisis secuencial permitió: clasificar las situaciones conflictivas habituales según el problema dominante que da inicio a un incidente; construir categorías sobre los procedimientos que utilizan niños y nińas ante situaciones conflictivas; caracterizar intervenciones de agentes educativos e identificar las normas expresadas en ellas; re-construir secuencias típicas y analizar la emergencia de ciertos comportamientos de los/as chicos/as en función de las reacciones de sus pares o a instancia de la actuación de los agentes educativos. 
Una vez ordenada y sistematizada la información, se configuraron grupos de comparación (Glasser \& Strauss, 1967; Huberman \& Miles, 1994; Rodríguez Gómez Gil \& García, 1999). Dentro de cada caso en estudio se agruparon los incidentes relevados según ocurrieran entre niñas, entre varones o entre niñas y niños. Se procedió a explorar recurrencias y pautas en cada uno, y luego entre sí, para posteriormente realizar la comparación entre los casos.

\section{Resultados}

\section{Caracterización de los incidentes conflictivos}

De acuerdo con criterio explicitado, se compararon las situaciones conflictivas según el sexo de los involucrados en el incidente. En el siguiente cuadro se exponen los motivos característicos y los procedimientos típicos en tres tipos de episodios conflictivos:

Cuadro 2. Incidentes conflictivos

\begin{tabular}{|c|c|c|c|}
\hline & $\begin{array}{l}\text { Entre chicas y } \\
\text { chicos }\end{array}$ & Entre varones & Entre chicas \\
\hline $\begin{array}{c}\text { Disputa } \\
\text { por el uso } \\
\text { de objetos }\end{array}$ & $\begin{array}{l}\text { Predomina: } \\
\text { verbalización } \\
\text { de pretensiones } \\
\text { (pedir, reclamar), } \\
\text { arrebato o despojo } \\
\text { de objetos, } \\
\text { demanda a agente } \\
\text { educativo, insultos } \\
\text { y burlas. } \\
\text { Hay disputas } \\
\text { originadas entre } \\
\text { niñas en las } \\
\text { que actúa un } \\
\text { compañero varón } \\
\text { como "auxiliar } \\
\text { de parte" y dirige } \\
\text { golpes y amenazas } \\
\text { hacia alguna } \\
\text { compañera. }\end{array}$ & $\begin{array}{l}\text { Predomina: reclamo } \\
\text { verbal, arrebato, } \\
\text { forcejeo, golpes, } \\
\text { insultos, amenazas, } \\
\text { demanda a agentes } \\
\text { educativos. }\end{array}$ & $\begin{array}{l}\text { Predomina: } \\
\text { reclamo } \\
\text { verbal, } \\
\text { demanda } \\
\text { a agente } \\
\text { educativo, } \\
\text { amenaza } \\
\text { de ruptura } \\
\text { vincular } \\
\text { o forcejeo } \\
\text { en torno al } \\
\text { objeto. }\end{array}$ \\
\hline
\end{tabular}




\begin{tabular}{|c|c|c|c|}
\hline $\begin{array}{l}\text { Hostiga- } \\
\text { miento }\end{array}$ & $\begin{array}{l}\text { Maltrato físico } \\
\text { y verbal dirigido } \\
\text { hacia algún/a } \\
\text { compañero/a en } \\
\text { particular. } \\
\text { Varones } \\
\text { protagonizan } \\
\text { agresiones físicas } \\
\text { en estos casos. }\end{array}$ & $\begin{array}{l}\text { Maltrato físico y verbal } \\
\text { dirigido hacia algún/a } \\
\text { compañero/a en } \\
\text { particular. }\end{array}$ & $\begin{array}{l}\text { No se } \\
\text { registra. }\end{array}$ \\
\hline $\begin{array}{c}\text { Juegos } \\
\text { corporales } \\
\text { que derivan } \\
\text { en pelea }\end{array}$ & No se registra. & $\begin{array}{l}\text { "Lucha y persecución". } \\
\text { Empieza con sentido } \\
\text { lúdico y termina en un } \\
\text { pleito. }\end{array}$ & $\begin{array}{l}\text { No se } \\
\text { registra. }\end{array}$ \\
\hline $\begin{array}{l}\text { Escalada de } \\
\text { agresiones } \\
\text { físicas }\end{array}$ & No se registra. & $\begin{array}{l}\text { Un niño golpea a otro } \\
\text { sin motivo aparente y } \\
\text { ambos se traban en una } \\
\text { situación de agresión } \\
\text { física. }\end{array}$ & $\begin{array}{l}\text { No se } \\
\text { registra. }\end{array}$ \\
\hline $\begin{array}{l}\text { Conflictos } \\
\text { vinculares }\end{array}$ & No se registra. & $\begin{array}{l}\text { La amenaza de ruptura } \\
\text { vincular emerge en } \\
\text { los pleitos, pero se } \\
\text { inserta como parte de } \\
\text { un conflicto por algún } \\
\text { objeto (por ejemplo, } \\
\text { se amenaza con "no } \\
\text { ser amigo" cuando } \\
\text { un niño se niega a } \\
\text { compartir un juguete). }\end{array}$ & $\begin{array}{l}\text { La disputa } \\
\text { se centra en } \\
\text { los vínculos. } \\
\text { Emergen } \\
\text { temas como } \\
\text { la cercanía, } \\
\text { las conexiones } \\
\text { íntimas y la } \\
\text { exclusividad } \\
\text { en las rela- } \\
\text { ciones (por } \\
\text { ejemplo, } \\
\text { jugar sólo con } \\
\text { una compa- } \\
\text { ñera). } \\
\text { Procedimien- } \\
\text { tos: exclusión } \\
\text { grupal y ame- } \\
\text { naza de rup- } \\
\text { tura vincular. }\end{array}$ \\
\hline
\end{tabular}


Según lo expuesto, los procedimientos desplegados varían según quiénes son los oponentes en la disputa y el motivo de la misma. Así, si bien los varones produjeron la mayoría de las actuaciones que involucraban violencia física o amenaza de agresión corporal, esto acontecía generalmente cuando la disputa era entre ellos, cuando eran convocados por las niñas para que intervengan en sus pleitos o en casos de hostigamiento a algún/a compañero/a. Mientras que en las disputas iniciadas entre niñas y varones por el uso de las cosas no fue tan notable que los niños golpearan a sus compañeras ni viceversa, más bien predominaron los reclamos verbales, las demandas a la maestra o los arrebatos, insultos y burlas.

La centralidad del cuerpo en las interacciones entre varones: agresiones físicas y juegos corporales

Según se expuso en el Cuadro 2, los incidentes conflictivos ocurridos entre varones se inician: a) cuando un niño golpea a otro (sin un motivo aparente) y se genera una escalada de actos de agresión física; b) en juegos corporales que empiezan con sentido lúdico y pueden terminar en un pleito entre las partes. En el siguiente esquema se aprecia la secuencia característica del tipo a):

Esquema 1. Escalada de agresiones físicas

\begin{tabular}{|l|l|}
\hline $\begin{array}{l}\text { Inicio } \\
\text { Agresión física sin motivo aparente: } \\
\text { golpe, empujón, tirón de cabello. }\end{array}$ & $\begin{array}{l}2 . \\
\text { a. Devolución de agresión física. } \\
\text { b. Demanda a agente educativo. }\end{array}$ \\
\hline $\begin{array}{l}\text { F. Sinalización: } \\
\text { a. Desisten de agresiones y continúa } \\
\text { actividad conjunta. } \\
\text { b. Separación de las partes } \\
\text { (abandono de juego o actividad o a } \\
\text { instancias de un agente educativo). }\end{array}$ & $\begin{array}{l}\text { S. Golpes. } \\
\text { b. Burlas. } \\
\text { c. Gestos intimidatorios recíprocos. }\end{array}$ \\
\hline
\end{tabular}


Mientras que los juegos de lucha y persecución se caracterizan por una escasa verbalización y un impactante despliegue de gestos y movimientos corporales, resulta notable que lo que empieza en actitud lúdica puede derivar en una situación conflictiva entre las partes. Esto sucedía cuando se quebraban las reglas del juego implícitas, por ejemplo, cuando alguien pegaba más fuerte que lo aceptable. Tal es el caso de dos niños que se reían mientras se amagaban con trompadas y patadas, pero cuando uno de ellos toma una mochila y golpea al otro, éste se larga a llorar, mira a la maestra y señala con el dedo a su compañero.

Esta fue una actividad lúdica en la que se han involucrado varios de los varones de la sala en cada caso, pero no todos los nińos observados. Al sistematizar la identificación de los participantes se advierte que no se han involucrado quienes, presumiblemente, ocupaban posiciones subordinadas en la red de relaciones entre pares. Se trata de aquellos niños que han sido víctima de hostigamiento o de despojo recurrente de objetos por parte de otros varones. Estos datos permiten inferir que este tipo de actividad corporal y gestual, que moviliza fuerza y destreza, puede significarse como un hito de diferenciación con las niñas, pero también como una forma de establecer distinciones entre los mismos varones. Podría pensarse que en los juegos corporales los procesos de diferenciación genérica acontecen tanto inter como intra género.

\section{El protagonismo de los niños en actos de hostigamiento}

Si bien los casos de hostigamiento no se registraron con frecuencia, es para destacar la emergencia en estos pequeños/as de tres-cuatro años de lo que se ha llamado como maltrato, abuso o bullying en la literatura específica del tema y que ha sido documentado sobre todo para chicos/as de escuelas primaria y secundaria (Del Barrio, Martín, Almeida \& Barrios, 2003). Respecto a la educación inicial Kochenderfer y Ladd (1996) han observado que la vivencia de victimización por parte de algunos de los pares es común en la formación de nuevos grupos. A continuación se exponen dos fragmentos de eventos registrados: 
1. Flavia está parada en un rincón de la sala y llora. En voz baja balbucea que se quiere ir a su casa. Diego se acerca y le pega una patada. La maestra interviene y reprende al niño.

Jonatan imita a Flavia y, en tono de burla, llora.

La maestra se ausenta de la sala.

La pequeña sigue llorando. Jairo y Jonathan le gritan que se calle. Flavia llora. Aldana grita: "Basta". Otros/as niños/as dicen: "Me está aturdiendo". Flavia llora y se rasca la cabeza. Diego se acerca y le grita: "Callate". Nicolás le tira con un juguete y le pega en la cabeza. Flavia se va de la sala. Nicolás abre la puerta y le grita: "Callate". La maestra regresa a la sala y le indica al niño: "Dejala, Nicolás".

Nicolás se va. Flavia regresa a la sala y le dice a la maestra que Nicolás le pegó. La maestra no responde (parece no escucharla). Jonatan repite en tono de burla: "Nicolás me pegó". Nicolás regresa y se para al lado de la puerta, mira a Flavia y le grita: "Maricona". Diego y Nicolás miran a Flavia, le tiran juguetes. Algunos/as chicos/as se ríen. Vuelven a tirarle juguetes. La maestra los llama y habla con ellos. Diego y Jairo le tiran juguetes a Flavia. Ella se sienta en el escritorio y los demás chicos/as se ubican en las mesas de trabajo. Comienzan a realizar la tarea indicada por la maestra (Caso 1).

2. Nahuel, parado en la puerta del baño, llama a Leandro. Cuando éste se acerca, Nahuel lo toma de un brazo y lo mete dentro. Alan entra al baño y cierra la puerta (aparentemente ambos le pegan a Leandro). Luego salen del baño y llaman a Cristian. Nahuel le dice: "Hacelo cagar al Leandro". Nahuel y Alan arriman la puerta y desde afuera espían. Ambos se ríen. Cristian sale del baño corriendo, Leandro lo persigue. Nahuel empuja a Leandro, quien continúa corriendo hasta que el primero le pone una caja de cartón en la cabeza. Leandro se la saca y le pega a Nahuel en la cara. Éste lloriquea. Entra la maestra y ve llorando a Nahuel. Interviene la docente (Caso 2).

Situaciones como las expuestas se registraron en los dos grupos del sector de pobreza y en ambos casos quienes asumieron el protagonismo en estos eventos, sobre todo cuando se trató de agresiones físicas, fueron determinados varones de la sala. A su vez, los destinatarios de este tipo de actuaciones eran niños/as que, en general, no se incluían en juegos o actividades con los demás, hablaban muy poco y emitían signos corporales y gestuales de retraimiento (se paraban en un rincón de la sala, permanecían encorvados y con el dedo en la boca o mirando hacia abajo). 
Estos actos de hostigamiento estarían ligados con las percepciones de algunos/as niños/as respecto de ciertos compañeros en aspectos como la apariencia, las habilidades comunicativas y expresivas. Según se indagó con las docentes, esos/as niños/as no presentaban tales dificultades en su contexto familiar, sino que se expresaban en el ámbito del jardín. Podría suponerse así que el escenario escolar genera, en algunos/as, ansiedades o miedos que se manifiestan en inhibiciones y retraimientos, y ello impacta en el proceso de entronización en las relaciones con los/ as compańeros/as.

Los varones que se implican en disputas entre niñas: "...ya está, ya le pegué..."

Un caso de especial interés para este trabajo se plantea cuando una disputa se inicia entre chicas, pero deriva en la intervención de algún varón. No hay registro del caso inverso, es decir, que un pleito iniciado entre varones diera lugar a la participación de una niña o que ellos solicitaran intervención a alguna compañera. El involucramiento de algunos varones se producía por motu proprio o por la solicitud de alguna de las niñas implicadas en el litigio, como se aprecia a continuación:

1. En el patio del jardín hay un grupo de chicas paradas detrás del tobogán, esperando su turno para lanzarse. Fernanda se para delante de Celeste, la empuja e intenta arrebatarle el lugar en la fila. Celeste le pega y se aleja del lugar. Fernanda comienza a llorar y Jairo, uno de sus compañeros, se acerca y le pregunta: - “Qué te pasó?".

Fernanda responde entre sollozos: - "La Celeste me pegó".

Jairo: - ¿Donde está?". Mira a su alrededor y sale corriendo. Se encuentra de frente con Celeste y le pega una cachetada. Vuelve hacia el tobogán y le dice a Fernanda: - "Ya está, ya le pegué".

Dalma, una nińa que había sido testigo de la escena, mira a Jairo y como justificándose le dice: - "Yo no fui Jairo, yo no le pegué".

(La maestra estaba en el otro extremo del patio). (Caso 1).

2. Cuatro niñas que jugaban juntas comienzan a disputar el uso de algunos juguetes. Se empujan y forcejean, intentando quitarse las cosas de las manos. 
Jazmín le advierte a Florencia:

- "Ahi te va a matar el Alan" (en referencia a uno de sus compañeros).

Jazmín se dirige a Alan y le dice con tono imperativo: - “Anda!, esa chica...” (señala a Florencia).

Alan abandona su juego y comienza a correr detrás de Florencia. Cuando la alcanza, la agarra del cuello, la tironea y le reclama que devuelva el juguete que tiene en la mano. Florencia se escapa y Alan la persigue. El niño toma un juguete, mira fijo a las nińas y amenaza con tirárselo a otra compañera. Florencia intenta tomar un juguete que está sobre la mesa, pero Alan se acerca, la empuja y se lo quita. El niño se aleja de Florencia, llevándose el juguete que ella pretendía usar. (La maestra no está en la sala). (Caso 2).

Se puede inferir que la agresión corporal que los varones son capaces de movilizar adquiere, para las niñas, en estas circunstancias, un doble sentido: protector, ya que a veces logran de este modo recuperar un objeto del que han sido despojadas, y amenazante, dado que son perseguidas, golpeadas o necesitan justificarse frente a sus compañeros para eludir un potencial castigo (por ejemplo, cuando Dalma adelanta una justificación en el episodio uno).

En general, estos incidentes prevalecieron en ausencia de las maestras. Cuando ellas percibieron situaciones de este tipo, desautorizaron este modo de proceder, aunque a veces el sentido expresado fue ambiguo (reprobación y legitimación). Así sucedió cuando un nińo se dirigía con gestos intimidatorios hacia una compañera que le había quitado la prensa de cabello a otra, y la docente le dijo: "Ahí va el defensor de los pobres". La idea de defensa de alguien en desventaja ("los pobres") podría hacer ingresar estos actos en un circuito de legitimación normativa.

Otra cuestión tiene que ver con la manifestación de estos incidentes según los casos seleccionados. Éstos se registraron en las salas del sector de pobreza estudiado, lo que hace considerar la incidencia de ciertas condiciones particulares del contexto en tales manifestaciones. Datos aportados por otras investigaciones realizadas en el barrio donde se ubican los centros permiten presumir que en este sector poblacional tendrían fuerte arraigo las desigualdades y jerarquías genéricas. Se 
documentaron situaciones de abuso, opresión y violencia ejercida por los hombres hacia las mujeres (López, Mandrile \& Perrino, 2002). Quizás estos modos puntuales de relación entre chicas y varones emergen de un contexto socializador marcado por relaciones de género asentadas en torno a dinámicas de dominación - subordinación.

Sin embargo cuando se explora quiénes han protagonizado estos incidentes se abre otra línea interpretativa. De un total de dieciocho episodios de este tipo han participado tres niños en el caso uno y dos niños en el caso dos. Estos chicos son los mismos que han mostrado con recurrencia otro tipo de actuaciones basadas en el uso de agresiones corporales o fuerza física (hostigamiento a compañeros/as, despojo de objetos mediante intimidación y participación frecuente en eventos de agresión física). Esto habilita a pensar en predisposiciones de algunos pequeños hacia una mayor violencia en sus actuaciones, que se encontraría potenciada por la persistencia (en algunos sectores sociales más que en otros) de pautas culturales de masculinidad asentadas en el uso de la violencia hacia las mujeres y los varones "no masculinos".

Finalmente, puede pensarse que, aun dentro de un mismo sector social, algunos niños, según sus experiencias biográficas, tienen más presiones que otros para adecuarse al género. Esto significa que la tensión para diferenciarse de las niñas y de los varones "no masculinos", aspecto del aprendizaje por reacción y represión de rasgos femeninos, los impulsaría a hacer un uso ostentoso de la capacidad intimidante y un empleo de la fuerza física como modo de exhibición del carácter masculino en las redes de relaciones con los pares.

Las intervenciones docentes y el refuerzo de la identidad de los "varones"

Los episodios conflictivos están por lo general sujetos a una intervención normativa por parte de un agente educativo. Se trata de actuaciones que: a) portan prescripciones, definen lo que es obligatorio hacer o no hacer; b) conllevan valoraciones de la actuación de los/as chicos/as desde parámetros normativos; c) pueden imponer sanciones específicas ante el comportamiento considerado transgresor a la norma. 
Del conjunto de intervenciones analizadas, en esta oportunidad se considerarán aquellas que expresan una significación diferencial de los comportamientos de niñas y varones. La forma característica que este tipo de actuación asume es la contrastación de los comportamientos del grupo "chicas" y el grupo "varones". Lo que aparece como rasgo saliente es la construcción discursiva de las niñas como sujetos que cumplen con las normas escolares, expresado comúnmente con los términos: "se portan bien”. En cuanto a los niños, prevalece una valoración negativa de sus comportamientos y se los constituye como clase problemática respecto al cumplimiento de las normas escolares, como se aprecia en los siguientes fragmentos de observaciones:

1. La maestra llama a todos/as para que vengan a sentarse en la parte delantera de la sala, luego les dice: "Atiendan una cosa que les voy a decir...Al primero que se siga portando mal le mando una nota en el cuaderno y le digo a la mamá que no lo mande más. Cada uno sabe a quién va dirigido el reto, sobre todo los varones, porque las nenas se están portando demasiado bien... cada uno sabe cómo se tiene que portar, ¿estamos de acuerdo?". (Caso 2).

2. Mientras izan la bandera algunos varones hablan y se ríen. Cuando terminan la rutina de izamiento, la maestra se dirige al conjunto de chicos/as y dice: "Me parece que vamos a dejar a las nenas nada más en el jardin, porque los varones no cantan, se empujan, se portan mal".

Luego, en la misma jornada y ante una situación en la cual un nińo escupe a otro, la docente separa a los chicos y les dice: "Venga, porque con los varones juntos no se puede. No puede ser que los varones cada vez que están juntos sea para pegarse, escupirse" (Caso 3).

Algunos episodios dan lugar a la aplicación de sanciones específicas, sobre todo cuando se producen eventos reiterados de agresiones físicas o desobediencia persistente a una orden dada por la maestra. En el siguiente esquema se consigna el castigo aplicado, el evento que le da lugar y a quién se aplica: 


\section{Esquema 2. Sanciones aplicadas}

\section{SANCIONES}

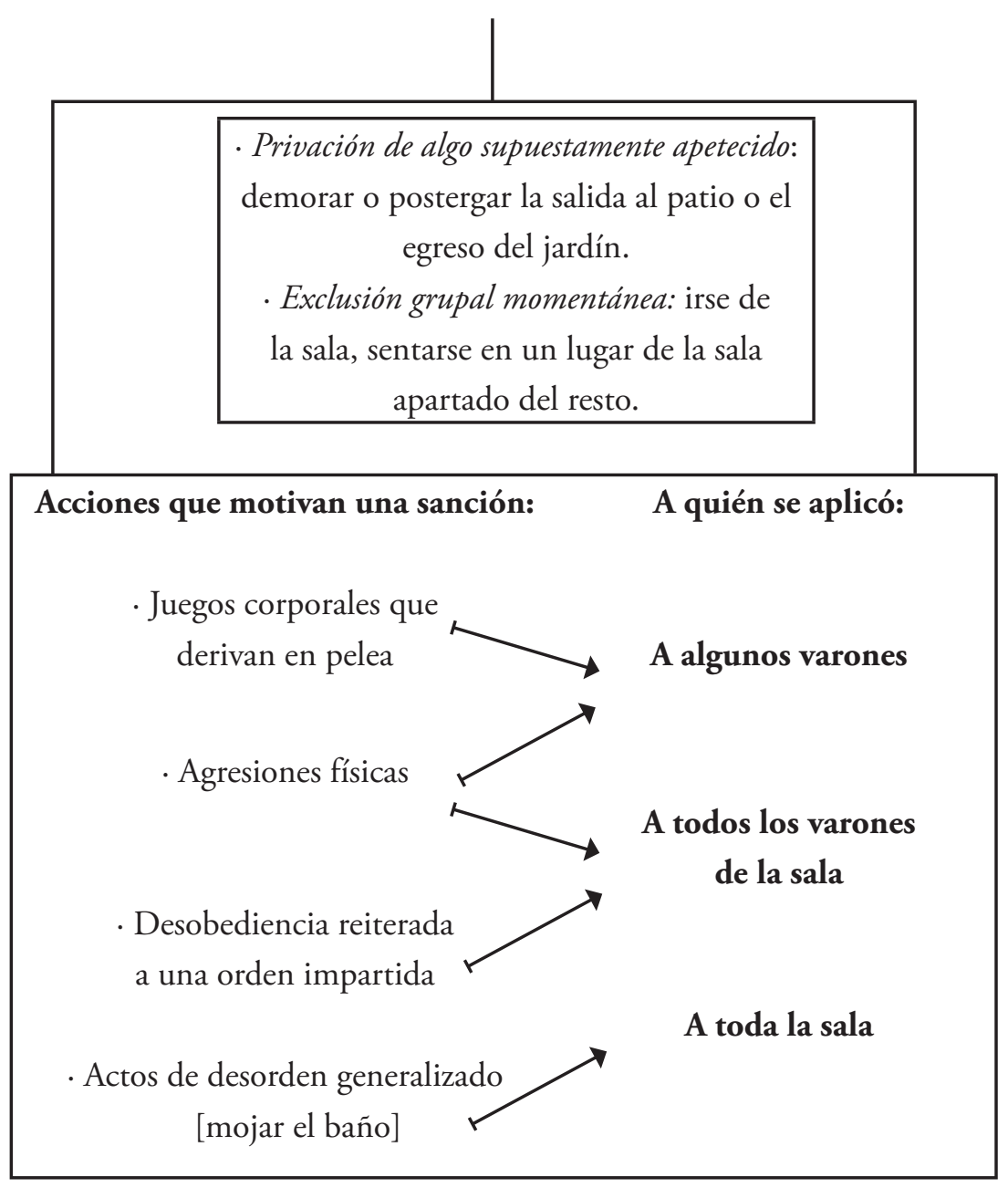

Algunas sanciones se aplican de modo particularizado, mientras que otras son colectivas, es decir, comprenden a todos los de una clase, más allá de que algunos de sus miembros no haya tenido participación en el evento que motiva la sanción. En los tres casos estudiados las sanciones colectivas han recaído sobre varones, salvo una ocasión, en la cual esta medida se aplicó a toda la sala. 
En términos de justicia retributiva, una sanción colectiva supone tratar de modo igual a circunstancias desiguales, ya que algunos son castigados por una falta que no cometieron, pero que se les imputa por el hecho de pertenecer a una clase de sujetos. Es decir, que aunque ciertos niños no hubieran estado implicados en el incidente en cuestión, todos son tratados como "problemáticos".

El castigo colectivo, cuando se dirige con recurrencia a una clase sexual -en este caso los varones- introduce una lógica de solidaridad (forzada) basada en el género. Esta forma de hacer a cada uno de los miembros del colectivo responsable por la falta de algunos se hace explícita en un enunciado, registrado en el siguiente episodio:

Los/as chicos/as han terminado de almorzar y la docente les indica que se formen en filas. Luego de formarse comienzan a caminar en dirección al salón de entrada del jardín. Algunos se empujan, un chico se cae y la maestra les ordena que regresen a la sala: - "A la sala los varones".

Una vez en la sala la maestra les dice:

- "Atiendan una cosa, ¿quieren salir?".

Jairo la interrumpe y dice: - "Él me empujó a mî" (señala a un compañero). La maestra continúa: - "Se forman bien, uno detrás del otro, qué vergüenza los varones".

Alan se defiende: - "Yo no fui".

La maestra replica: - "no importa, por uno son todos: un nene se cayó y lo pisaron, en vez de esperar a que se levante. Podrian haberlo lastimado".

Luego de unos instantes, la docente les pide que se dirijan al salón y agrega: - "Se sientan y esperan porque van a salir primero las nenas, aunque estén las mamás de ustedes esperándolos". (Caso 2).

El enunciado "por uno son todos" introduce explícitamente la idea de que la co-responsabilidad es genérica. Estos actos de sanción que tienen como destinataria a una categoría sexual establecen coordenadas identificatorias (los varones deben responder por los varones) y posicionan a niños y niñas en determinados lugares en una red de relaciones. Así, tanto efectiva como representacionalmente las niñas se acaban uniendo con las niñas y los varones con los varones. Por ello, son micro situaciones 
cotidianas donde se promueven identidades de género. En los casos estudiados, la identidad de los varones encuentra un núcleo de significación en su carácter de clase problemática con respecto a la disciplina y al orden normativo.

La aplicación de sanciones colectivas cuyo alcance es la clase sexual, así como las intervenciones donde se contrasta y/o valora de modo diferencial el comportamiento de chicas y varones, indican que el niño o la niña va ingresando en una lógica de significación por referencia al género. Bien es cierto que en muchas ocasiones los varones han recibido calificaciones positivas como conjunto o personalmente (hay registro de situaciones donde se felicita o se elogia el comportamiento de alguno, de un grupo o de toda la clase varones); no obstante, fue recurrente en los tres casos la significación como problemática de toda la clase, en intervenciones docentes motivadas por el comportamiento de algunos de ellos (sobre todo en los casos de agresiones físicas y comportamientos disruptivos reiterados).

En este eje analítico las entrevistas realizadas con las maestras aportan dos cuestiones. Las docentes del caso 1 y del caso 2 dicen que tratan por igual a chicas y a varones, es decir, no reconocen que puedan estar generando diferenciaciones entre ambos, como afirma una de ellas: “... yo no los manejo a ellos como 'chicos' y 'chicas', para mí son todos iguales, delante de ellos, son todos iguales". Mientras que la maestra del caso 3 destaca que para ella presenta mayor dificultad intervenir en los conflictos entre niñas por el tipo de agresividad implicada en sus disputas (que ella denomina como "violencia simbólica”), que puede ser tan o más lesiva que la envuelta en los pleitos entre varones. Sin embargo, en sus actuaciones prevalecen tipificaciones más negativas hacia ellos y cuando aplica sanciones colectivas se dirigen a los varones de la sala.

Que los niños como clase hayan recibido epítetos más negativos y hayan sido sancionados colectivamente podría interpretarse, tal como se propone en otras investigaciones, como acciones orientadas por un marco de género que, a modo de contexto simbólico, genera estereotipos sobre el comportamiento de los varones: que son desafiantes, transgresores, traviesos, inquietos, disruptivos (Younger et al., 1999). 
No obstante se puede pensar también que actuaciones como las señaladas remiten a motivos prácticos. Los procedimientos que usaron con más frecuencia los niños -ligados a actuaciones corporales, que muchas veces ponen en juego la integridad física- plantearían a las docentes una situación de urgencia sobre la que rápida y espontáneamente deben intervenir. Por su parte, las niñas han sido más propensas a dirimir sus disputas "por lo bajo", utilizando formas de "agresión relacional" (Crick, et al, 1996) y simbólica (difamaciones entre compañeras o burlas). En este sentido, para una maestra que está tratando de conducir la realización de una tarea escolar dos varones que se pegan o que corren por la sala no supone lo mismo que dos niñas que se miran con gestos de desdén.

\section{Comentarios finales}

En el análisis presentado en este trabajo hay coincidencias con la literatura existente en cuanto al estilo rudo que exhiben los varones y su tendencia a desplegar actuaciones de violencia corporal e intimidaciones en las interacciones entre compañeros (Crick et al., 1995; Lloyd, 1995; Crick et al., 1996; Renold, 2001; Wenetz et al., 2006).

Ahora bien, la mayoría de las actuaciones que involucraban violencia física acontecieron cuando la disputa era sólo entre ellos o bien cuando eran convocados por las niñas para que se interpongan y resuelvan sus pleitos. Desde algunas posiciones se ha sostenido, entre otras explicaciones, que en lo fundamental la tendencia agresiva en los varones está determinada biológicamente y se relaciona con la producción de andrógenos, especialmente testosterona. Las observaciones de este estudio llevan a subrayar el papel de la mediación simbólica: la interpretación de la situación sería clave en la activación de determinados procedimientos. De modo práctico se pondría en juego, al decir de Basil Bernstein (1990), una regla que regula la interpretación de los significados y las realizaciones. Esto orienta a los niños para escoger el significado relevante en una ocasión determinada y para producir el comportamiento "apropiado" dentro de un contexto; por ejemplo, que la agresión física es una regla para pleitos entre varones. 
El hostigamiento, el despojo de objetos a algún compañero "retraído", las intimidaciones, las agresiones físicas, el "ajusticiamiento" a alguna compañera, parecen ser algunas formas por las cuales ciertos varones ejercen el dominio físico sobre sus compañeros/as. Por cierto que cabría profundizar la exploración de cómo éstas, que se caracterizan por ser actuaciones ajustadas a los valores de la masculinidad hegemónica, se insertan en un juego más amplio de relaciones. Estas maneras de proceder permitirían obtener beneficios en términos de imagen pública, constituirían parte de la identidad de los pequeños como varones masculinos ("no niña", "no maricón”). Pero también redunda en beneficios prácticos. Es decir, no sólo "ganan" en la construcción de una imagen positiva cuando son convocados por las niñas para que actúen en su defensa ("protectores"), sino que también el juego de adjudicaciones y asunciones de posiciones dominantes se liga con privilegios que se establecen de hecho para el uso de objetos (acumular más de lo que corresponde, por ejemplo).

Por otro lado, la incidencia de las actuaciones de agresión física es mayor en los chicos del sector de pobreza estudiado (Casos 1 y 2). Asimismo, allí se registraron las agresiones de los varones hacia las niñas cuando intervinieron en disputas iniciadas entre ellas y los actos de hostigamiento. Estas pautas de relación infantil pueden encontrar una interpretación en la conjunción de las siguientes hipótesis: las presiones, más acuciantes en algunos varones que en otros, para "adecuarse al género", marcando en sus actos diferencias con las niñas y con los "niños no masculinos"; un contexto socializador local caracterizado por relaciones de género asentadas en torno a dinámicas de subordinación-dominación; un contexto cultural donde persisten significaciones de masculinidad asociadas con el vigor y la fuerza, el control del dolor físico, el ocultamiento de las emociones, las actitudes temerarias, la tendencia al dominio.

En atención a lo expuesto es crucial y estratégica la mediación de los adultos para cuestionar distintas formas de maltrato, prepotencia y estereotipos sexistas. El ámbito educativo es clave para el cambio de estructuras simbólicas. Sin embargo, nuestro trabajo nos hace advertir la necesidad de la formación básica y continua del profesorado en perspectiva de género, con la incorporación de la sensibilización como componente 
necesario de la capacitación. Por sensibilización se entiende aquellos procesos dirigidos que apuntan a que las personas puedan reconocer obstáculos y dificultades en la visibilización de problemas sociales y entender su propia participación e implicación subjetiva en el mantenimiento o resolución de los mismos a través de discursos y acciones (Paulín, Rodigou \& Tomasini, 2009).

En este estudio aparece como un aspecto relevante una forma de marcación de género que se expresa predominantemente como la valoración diferencial del comportamiento de la clase nińas y la clase varones. Han sido contundentes expresiones como "con los varones juntos no se puede", "por uno son todos", "qué vergüenza los varones". Las recurrentes calificaciones de problemáticos dirigidas a los varones estarían relacionadas con los procedimientos que algunos de ellos usaron con más frecuencia, lo cual los habría puesto en colisión abierta y explícita con el orden normativo escolar. No obstante, se constituyen de este modo marcas de identidad significativas. Esto instala formatos de comparación y competencia entre la "clase niñas" y la "clase varones" y es parte del entramado que sostiene la reproducción de estereotipos sexistas.

\section{Referencias}

Acuña, M. E. (2004). Bulla y bullicio en el aula. La interferencia de la clase, la etnicidad y el género en el proceso de enseñar y aprender. En M. Sadler, M.E. Acuña \& A. Obach (Eds.). Nacer, educar, sanar (pp. 67-102). Santiago de Chile: Catalonia.

Alonso, G. \& Morgade, G. (2008). Educación, sexualidades y géneros: tradiciones teóricas y experiencias disponibles en un campo en construcción. En G. Morgade \& G. Alonso (Eds.). Cuerpos y sexualidades en la escuela: de la normalidad a la disidencia (pp. 1939). Buenos Aires: Paidós.

Beer, D. (2008). Visiones y discursos en la educación física de la escuela primaria. En G. Morgade \& G. Alonso (Eds.). Cuerpos y sexualidades en la escuela: de la normalidad a la disidencia (pp. 149173). Buenos Aires: Paidós.

Bernstein, B. (1990). Poder, educación y conciencia. Sociología de la transmisión cultural. Barcelona: El Roure. 
Bigler, R., Jones, L. \& Lobliner, D. (1997). Social Categorization and the Formation of Intergroup Attitudes in Children. Child Development, 68(3), 530-543.

Blanco, M. T., García, S., Grissi, L. \& Montes, L. (2006). Relaciones de violencia entre adolescentes. Influencia de la familia, la escuela y la comunidad. Buenos Aires: Espacio.

Burín, M. \& Meler, I. (2000). Varones. Género y subjetividad masculina. Buenos Aires: Paidós.

Butler, J. (2001). El género en disputa. El feminismo y la subversión de la identidad. México: Paidós.

Colomina, R., Mayordomo, R. \& Onrubia, J. (2001). El análisis de la actividad discursiva en la interacción educativa. Algunas opciones teóricas y metodológicas. Infancia y Aprendizaje, 93, 67-80.

Connel, R. (1995). Masculinities. Cambridge: Polity Press.

Conway, J., Bourque, S. \& Scott, J. (1996). El concepto de género. En M. Lamas (Ed.). El género: la construcción cultural de la diferencia sexual (pp. 21-33). México: PUEG y Miguel Ángel Porrúa Grupo Editorial.

Crick, N. \& Grotpeter, J. (1995). Relational Aggression, Gender, and Social-Psychological Adjustment, Child Development, 66, 710-722.

Crick, N., Bigbee, M. \& Howes, C. (1996). Gender Difference in Children's Normative Beliefs about Aggression: How Do I Hurt Thee? Let Me Count the Ways. Child Development, 67, 1003-1014.

Del Barrio, A., Martín, E., Almeida, A. \& Barrios, A. (2003). Del maltrato y otros conceptos relacionados con la agresión entre escolares y su estudio psicológico. Infancia y Aprendizaje, 26(1), 9-24.

Dumais, S. (2002). Cultural Capital, Gender, and Scholl Success: The Role of Habitus. Sociology of Education, 75, 44-68.

Flick, U. (2004). Introducción a la investigación cualitativa. Madrid: Morata.

Gilmore, D. (1994). Hacerse hombre. Concepciones culturales de la masculinidad. Barcelona: Paidós.

Glaser, B. \& Strauss, A. (1967). The Discovery of Grounded Theory. Chicago: Aldine.

Hartup, W. (1995). Las amistades infantiles. En J. Palacios, A. Marchesi \& Carretero, M. (Eds.). Psicología evolutiva 2. Desarrollo cognitivo y social del niño (pp. 389-421). Madrid: Alianza Editorial.

Huberman, A. \& Miles, M. (1994). Data Management and analysis methods. En N. Denzin \& Y. Lincoln (Eds.). Handbook of Qualitative Research (pp. 428-444). California: Sage Publications. 
Kochenderfer, B. \& Ladd, G. (1996). Peer Victimization: cause or consequence of school maladjustment. Child Development, 67(4), 1305-1317.

Leaper, C. (1992). Gender Identities and Education: The impact of Starting School. American Journal of Psychology, 108(2), 300304.

Levy, G., Taylor, M. \& Gelman, S. (1995). Traditional and Evaluative Aspects of Flexibility in Gender Roles, Social Conventions, Moral Rules, and Physical Laws. Child Development, 66, 515-531.

Lloyd, B. \& Duveen, G. (2003). Un análisis semiótico del desarrollo de las representaciones sociales de género. En J. A. Castorina (Ed.). Las representaciones sociales: problemas teóricos y desafios educativos (pp. 41-63). Barcelona: Gedisa.

Lomas, C. (2007). La escuela es un infierno. Violencia escolar y construcción cultural de la masculinidad. Revista de Educación, 342, 83-101.

López, J., Mandrile, V. \& Perrino, S. (2002). Prácticas socializadoras en un grupo de madres de un barrio periférico de la ciudad de Córdoba. Tesis de licenciatura no publicada. Córdoba: Universidad Nacional de Córdoba.

Marsh, H., Parada, R., Seeshing, Y. \& Healy, J. (2001). Aggressive School Troublemakers and Victims: A longitudinal Model Examining the Pivotal Role of Self-Concept. Journal of Educational Psychology, 93(2), 411-419.

Olavarría, J. (2003). Los estudios sobre masculinidades en América Latina. Un punto de vista. Anuario Social y Político de América Latina y el Caribe, 6, 91-98. Caracas: Flacso/Unesco/Nueva Sociedad.

Paulín, H., Rodigou, M. \& Tomasini, M. (2009). Recomendaciones para políticas de promoción de la convivencia escolar. Ponencia presentada en La Universidad en la Sociedad, Córdoba, Argentina.

Renold, E. (2001). Learning the 'Hard' Way: boys, hegemonic masculinity and the negotiation of learner identities in the primary school. British Journal of Sociology of Education, 22(3), 369-385.

Rodríguez Gómez, G., Gil, J. \& García, E. (1999). Metodología de la investigación cualitativa. Málaga: Ediciones Aljibe.

Stake, R.E. (1998). Investigación con estudio de caso. Madrid: Morata.

Valles, M. (1999). Técnicas cualitativas de investigación social. Reflexión metodológica y práctica profesional. Barcelona: Síntesis Sociológica.

Welch-Ross, M. \& Smith, C. (1996). Gender-Schema Development and Children's Constructive Story Memory: Evidence for a Developmental Model. Child Development, 67, 820-835. 
Wenetz, I., Stigger, M. \& Meyer, D. (2006). A construção do Gênero no espaço escolar, Revista Movimiento, 12(1), 59-80.

Ynoub, R. (2002). Semiosis y subjetividad en la experiencia coexistencial. Elementos narrativos, lógicos y retóricos para describir la conducta normativa en la primera infancia. Tesis Doctoral no publicada. Buenos Aires: Facultad de Psicología, UBA.

Younger, M., Warrington, M. \& Williams, J. (1999). The Gender gap and Classroom Interaction: reality and rhetoric? British Journal of Sociology of Education, 20(3), 325-341.

Zattara, S. \& Skoumal, G. (2008). Chicas y chicos de sectores populares transitando la escuela media. En G. Morgade \& G. Alonso (Eds.). Cuerpos y sexualidades en la escuela: de la normalidad a la disidencia (pp. 175-194). Buenos Aires: Paidós.

Fecha de recepción: 03 de mayo de 2010.

Fecha de aceptación: 27 de julio de 2010. 